\begin{tabular}{|c|c|c|}
\hline \multirow[b]{2}{*}{ 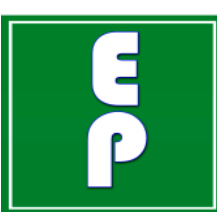 } & Int.J.Curr.Microbiol.App.Sci (2021) 10(12): 183-189 & \\
\hline & $\begin{array}{l}\text { International Journal of Current Microbiology and Applied Sciences } \\
\text { ISSN: 2319-7706 Volume } 10 \text { Number } 12 \text { (2021) } \\
\text { Journal homepage: } \underline{\text { http://www.ijcmas.com }}\end{array}$ & 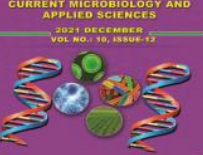 \\
\hline PUBLISHERS & & www: ijcmas.com \\
\hline
\end{tabular}

\title{
Ecological Features of Winter Wheat Agrocenoses in the Conditions of the Khorezm Oasis in Uzbekistan
}

\author{
A. A. Masharipov and S. M. Mambetullaeva* \\ Urgench State University, Uzbekistan \\ *Corresponding author
}

\section{Keywords \\ Irrigated land, sowing time, environmental factors, winter wheat \\ Article Info \\ Received: \\ 11 November 2021 Accepted: \\ 05 December 2021 \\ Available Online: \\ 10 December 2021}

\section{A B S T R A C T}

The article highlights the research on the ecological features of winter wheat and cotton agrocenoses in the conditions of the Khorezm oasis in Uzbekistan. The influence of environmental factors makes significant adjustments to the growth processes and the creation of the productive potential of plants. Environmental factors, such as water consumption, sowing time, irrigation rates and other factors influence on optimal growth and development of winter wheat. The sowing time of the irrigated lands of the Khorezm region in Uzbekistan has a very significant impact on the effective growth of plants.

\section{Introduction}

Throughout the world, the ecological situation at the present stage of agricultural development is characterized by a high level of anthropogenic impact on agroecosystems, which is associated with a deterioration of soil fertility. Human economic activity in agrocenoses has a very intense impact on the biosphere, exerting both positive and negative effects on various parameters of the natural environment. The sustainable growth of agricultural production is currently associated with the intensification of the technological process of cultivation aimed at creating highly productive agrophytocenoses, improving the quality of grain and reducing its losses from weeds, diseases, pests and stressful weather events while maintaining the ecological safety of the environment, reducing resource and energy costs.

The general ecological situation largely determines the level of productivity in agrocenoses, therefore, methods for obtaining high yields of ecologically clean products should take into account the increasing impact of anthropogenic activities on the environment. Hazardous soil cultivation, illiterate use of intensification agents, the use 
of heavy agricultural machinery, man-made emissions and other impacts are the main anthropogenic factors leading to negative consequences in agrocenoses. To solve environmental problems, it is important to take into account the complex nature of the use of intensification means and modern technologies for the cultivation of agricultural crops in agriculture, to monitor the state of soils and end products.

The influence of environmental factors makes significant adjustments to the growth processes and the creation of the productive potential of plants. By their nature, extreme factors are different, and their effect is differentiated into adaptive, damaging and lethal. The stronger the "pressure" of the environment, the higher the energy consumption of a plant to maintain a stable level of its vital activity $(2,4)$.

Resistance is understood as the ability to maintain the normal functioning of the body when exposed to extreme factors. Resistance is a genetically controlled heritable trait, characterized by the normal reaction of the genotype (5). The realization of resistance is manifested only when the plant is under the influence of an extreme factor. The main environmental impacts, the action of which causes a response and reduces resistance, include extreme temperatures, strong insolation, moisture deficit, excess salts, etc. $(1,3,6)$.

The problem of adaptation has always occupied a central place in evolutionary theory, and especially in selection $(4,5)$. The term "adaptability" refers to the body's ability to adapt to a particular environment. Structural or functional changes in an organism that increase its viability, survival, rate of reproduction are called adaptability in population genetics $(2,3)$. Adaptability is manifested through the acquisition of features (adaptive) and adaptive functions that contribute to the adaptation of organisms to certain environmental conditions $(4,6)$.

Diverse ecological factors are subdivided into climatic, soil-ground, topographic, biotic and anthropogenic factors. The first three factors are combined into a group of physicalgeographical (abiotic) factors and are basic for the plant habitat. Periodic environmental factors are distinguished naturally: daily and seasonal changes in climatic conditions, the length of the day, which determine biological cycles (5).

Productivity of agricultural crops, including cereals depends on many factors, among which the weather plays a significant role.

\section{Materials and Methods}

The studies were conducted in the experimental fields of the Khorezm branch of UzPITI. The Khorezm branch of UzPITI is located on the eastern outskirts of Urgench (600 69 longitudes and 41053 latitudes) and covers a total area of 145 hectares. The absolute height of the area above sea level is $99 \mathrm{~m}$. The soil of the experimental area is old irrigated meadow alluvial soil, which has low salinity, medium sandy and groundwater levels are at a depth of 1.5-2.0 m.

Khorezm region is located in the northwestern part of Uzbekistan in the Lower Amudarya region, in the Khorezm plain, which is part of the Turan lowland. The territory of the region is small, extending from south-east to north-west, and declining in the same direction. The northernmost point of the region is in Gurlan district, the southernmost point is in Hazarasp district, on the Amudarya river of Kyzylkum state reserve, the westernmost point is in Shavat district, the eastern point is in Bukhara region of Hazarasp district. The region is located between $40^{\circ}$ and 
$42^{\circ}$ north latitudes and $60-62^{\circ}$ east longitudes. The region is $280 \mathrm{~km}$ from northwest to southeast. The city of Urgench is $80 \mathrm{~km}$ long from west to east and covers an area of 6.05 thousand $\mathrm{km}^{2}$. The main agricultural part of the left bank of the region is covered by alluvial deposits of the ancient Amudarya delta. The thickness of the alluvial deposits is between a few $\mathrm{cm}$ and 80-100 meters on the left bank. The region is located in the desert zone, south of the temperate zone.

The Turan plain, where the territory is located, is open on the north and east, and blocked on the south and west. Therefore, moderately humid and cold northern air masses enter the territory of the region from the north, northwest, and the mountains block the tropical humid air masses from the south.

In the formation of the regional climate, especially in the current situation, when the Aral Sea does not play a significant role, the impact of the desert on the oasis has increased, and in the summer months the heat activity is much stronger than before.

The average annual temperature in the region reaches $+10,+12^{\circ} \mathrm{C}$, in the southern part of the region it is $+15^{\circ} \mathrm{C}$. This figure is $14^{\circ} \mathrm{C}$ in Urgench. In the southern regions, the average January temperature is around $-5^{\circ} \mathrm{C}$, while in the rest it is $-4,-5^{\circ} \mathrm{C}$. The temperature in the oasis drops to $-32^{\circ} \mathrm{C}$ during the winter months. The average temperature in July is $+27.5^{\circ} \mathrm{C}$, while in Urgench it is $+27.3^{\circ} \mathrm{C}$ (Table 1). The average annual number of frost-free days in the region is 200 days, 204 in the southern part and 195 in the northern part.

The fact that the area of the region extends considerably from northwest to southeast results in an average weekly vegetation difference between the northern and southern regions of average temperature. In general, the agro-climatic conditions of the region allow growing cotton, rice, corn, figs, grapes, melons, pomegranates and other heat-loving crops. The region, along with the Republic of Karakalpakstan, is one of the northernmost cotton-growing regions.

\section{Results and Discussion}

The territory of the region is located in three natural geographical districts - Lower Amudarya, Kyzylkum and partly Unguzorti Karakum. The main part of the left bank of the region, ie the core, is located in the ancient delta of the Amudarya, in the part of the Khorezm natural geographical region of the Lower Amudarya natural-geographical district. These landscapes mainly cover the ancient slopes or high terraces of the Amudarya. The area consists mainly of irrigated agricultural landscapes. The oasis is surrounded by the Karakum Desert, and in some places it penetrates into the oasis in the form of desert (Fig.2). The total area of agricultural land in the region is 605,000 hectares. However, about 330,000 hectares of it are irrigated. Of this amount, 25,000 hectares are tugai and forest areas, some to residential areas, and the rest is the desert region, which is currently only available for livestock.

Despite the fact that the territory of the region is small and flat, as a result of natural conditions, the influence of natural components, as well as under several thousand years of human economic activity, soils are formed that differ to some extent.

If timely and regular reclamation measures are carried out in the crops of the region, and the surrounding land reclamation facilities are not kept at the level of norms, the soils will quickly become saline and out of circulation. Soil condition, in particular, salinity, filtration capacity, is related to its mechanical composition. Depending on the mechanical 
composition and layer structure of the soils distributed in the region, soil scientists divide them into 6 main groups - sandy, loamy, light sandy, medium sandy, heavy sandy, clayey. Medium sandy (30\% of the land fund) and light sandy (21.6\%) soils are the most common in the region.

In the conditions of Khorezm region, when the groundwater or groundwater level approaches $150 \mathrm{~cm}$ above the soil surface, the soil begins to moisten the soil surface and plant roots through voids and pores. The rise of the water level above $150 \mathrm{~cm}$ intensifies this process and the water vapor itself carries minerals to the top layer of the soil.

The most favorable conditions for plant growth are created when the soil moisture is not less than 75-80 percent of the limited field moisture capacity. The moisture absorption of winter wheat from the soil stops when the moisture in the soil is equal to the moisture content. Depending on the mechanical composition of the soil, the physical properties of the water and the chemical composition, the moisture content of the soil varies relative to the weight of the absolute dry mass of the soil.

This moisture content is $1-3$ percent in sandy soils, 3-5 percent in loamy and light sandy soils, 6-12 percent in medium and heavy sandy soils, and $12-18$ to 22 percent in loamy soils. During the growing season of winter wheat, depending on the growing conditions, it is possible to consume $2000-4000 \mathrm{~m}^{3} / \mathrm{ha}$ in dry farming, $6000 \mathrm{~m}^{3} / \mathrm{ha}$ and more in irrigated lands.

The extent to which a plant uses moisture can be determined by the transpiration coefficient. The average transpiration coefficient in winter wheat can be 450, and in some years 700 or more. Under favorable conditions for plant growth, the transpiration coefficient can be reduced to $350-300$ if the farming culture is high. The magnitude of the transpiration coefficient of water consumption depends not only on the growth conditions, but also on the age of the plant, the intensity of growth processes. At the beginning of the growth period, $800-1000 \mathrm{~m}^{3}$ of water is used to produce 1 ton of dry matter. With plant aging, this figure decreases and reaches 150 to 200 $\mathrm{m}^{3} / \mathrm{t}$ by the end of the growth period. However, these measurements differ significantly from the average. Water consumption is low when the weather is low, it is high when it is hot, dry.

Table.1 Dynamics of long-term indicators of monthly and average monthly data on air temperature in Khorezm region (2018-2020)

\begin{tabular}{|c|c|c|c|c|c|c|c|c|c|c|c|c|c|c|c|}
\hline \multirow[t]{2}{*}{ Meteostations } & \multicolumn{12}{|c|}{ Average monthly air temperature, ${ }^{\circ} \mathrm{C}$} & \multicolumn{3}{|c|}{$\begin{array}{c}\text { Annual air } \\
\text { temperature, }{ }^{\circ} \mathrm{C}\end{array}$} \\
\hline & 1 & 2 & 3 & 4 & 5 & 6 & 7 & 8 & 9 & 10 & 11 & 12 & Average & Max & Min \\
\hline Khiva & $-4,5$ & $-1,5$ & 5,6 & 14,5 & 21 & 25,3 & 27,4 & 24,9 & 18,8 & 11,1 & 4 & $-1,5$ & 12,1 & 44 & -31 \\
\hline Urgench & $-5,1$ & $-2,2$ & 5 & 13,8 & 21 & 25,3 & 27,3 & 25,1 & 18,8 & 10,8 & 3,1 & -2 & 11,8 & 43 & -32 \\
\hline Termiz & 2,8 & 5,7 & 11,5 & 18,5 & 24,5 & 29,3 & 31,4 & 29,6 & 23,3 & 16,9 & 10,1 & 4,8 & 17,4 & 48 & -21 \\
\hline Churuk & $-11,1$ & $-8,9$ & 0 & 9,6 & 18,1 & 23,7 & 27,3 & 24,9 & 17,3 & 7,3 & 5,5 & $-4,8$ & 8,6 & 44 & -37 \\
\hline
\end{tabular}


Fig.1 Khorezm oasis (left) and desert Kyzylkum (right)

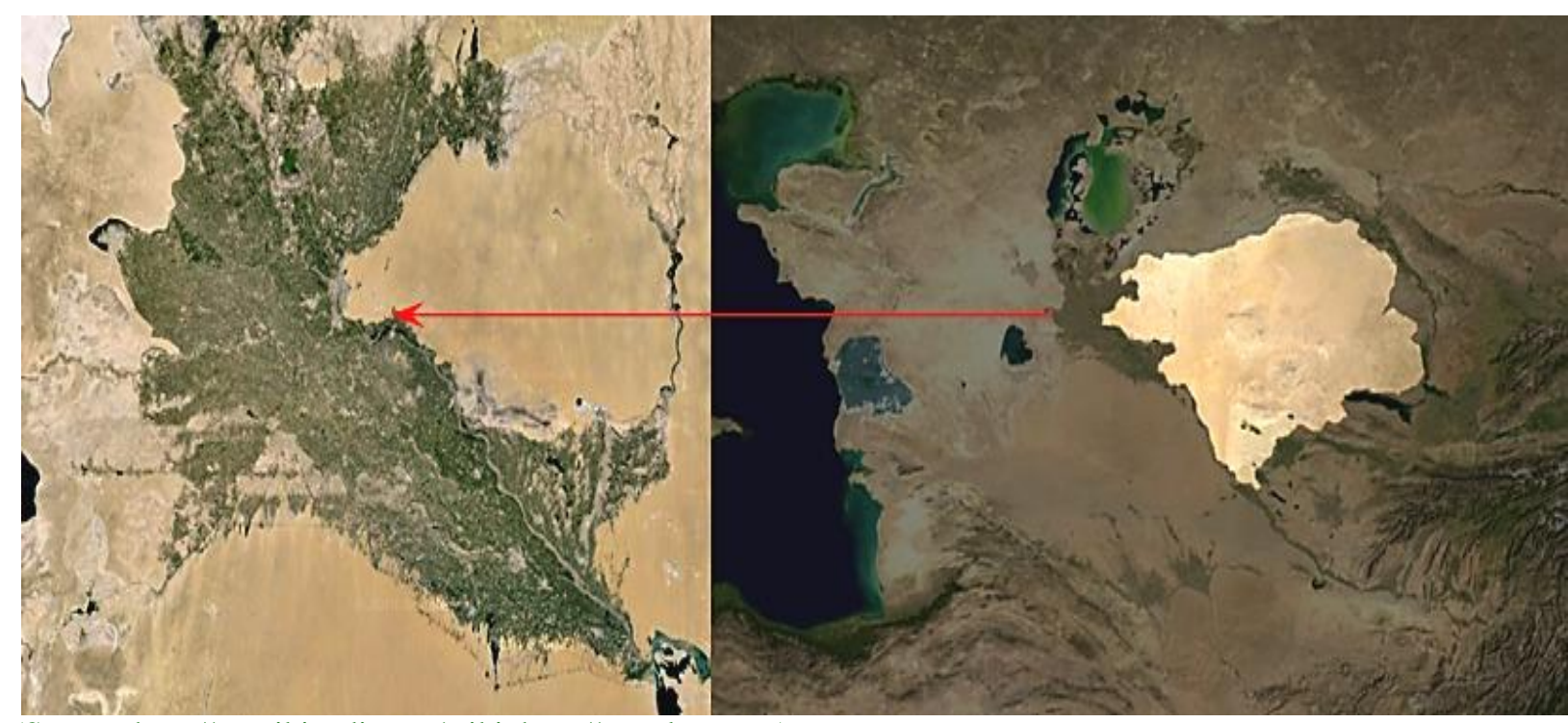

(Source: http://ru.wikipedia.org/wiki, http://google.maps )

Fig.2 Map of landscapes of Khorezm region

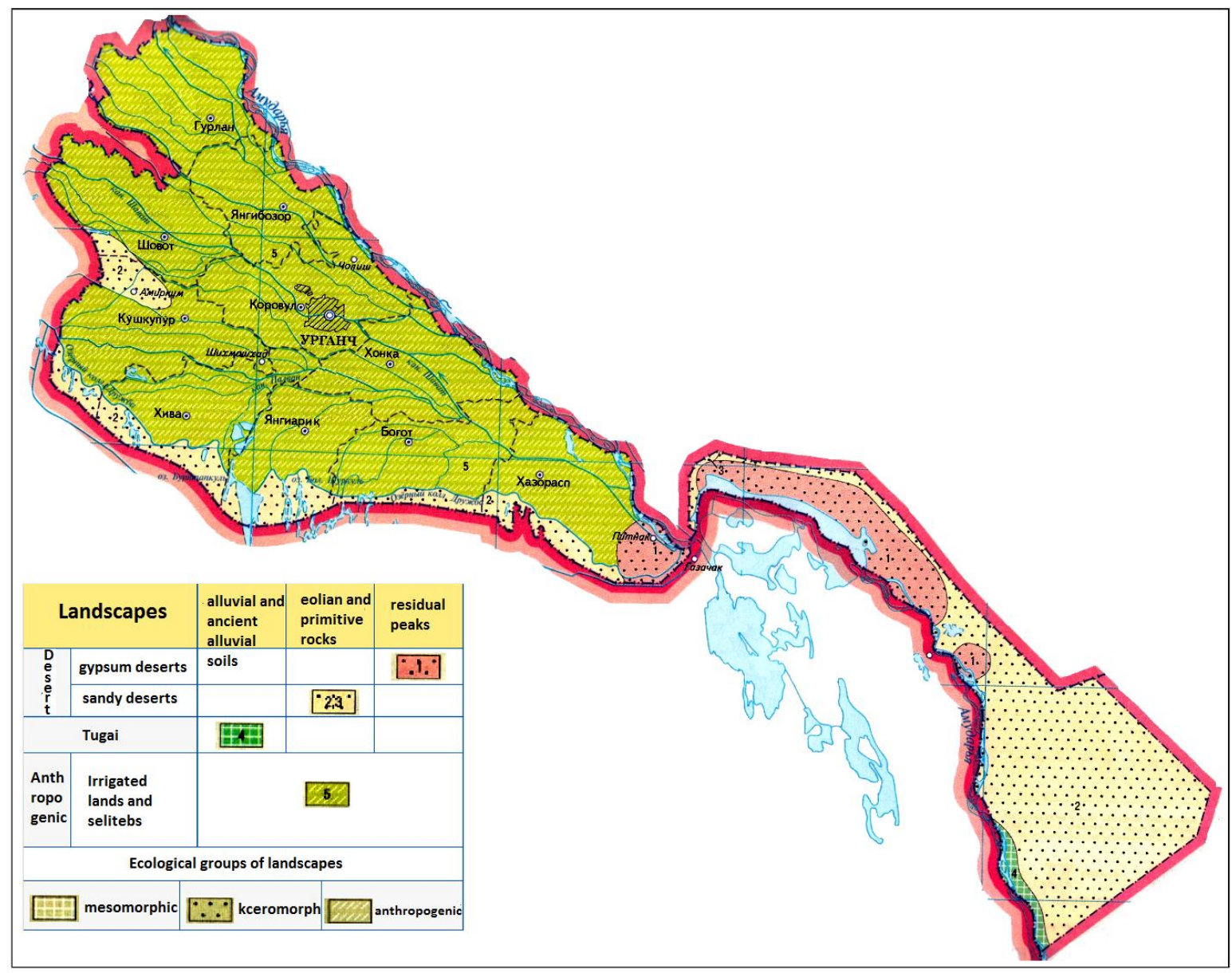


It is difficult to distinguish the water that the plant consumes during the cultivation of winter wheat from the water that evaporates from the soil. Therefore, the amount of water consumed from grains in a given unit is calculated by comparing the size of the grain or the total mass of the crop. This figure is $400-600 \mathrm{~m}^{3} / \mathrm{t}$ for total mass and $800-1200 \mathrm{~m}^{3} / \mathrm{t}$ for grain, depending on the growing conditions of winter wheat.

Demand for water increases during the growing season of winter wheat. In order for the seeds to germinate evenly, it is necessary that the moisture content of the soil is more than $10 \mathrm{~mm}$ at a thickness of $10 \mathrm{~cm}$. Grasses need less water because their waterevaporating leaf surface is low. The plant consumes the most water from the tube to the milk ripening of the grain.

In the arable lands of Uzbekistan in the foothills, the very deep groundwater prevents the continuous and moderate rise of moisture from the lower layers of the soil profile through the capillaries.

Therefore, the main source of soil moisture in the main part of the arable land in the country is atmospheric precipitation. In arable lands, where winter wheat is grown, the water regime of the soil depends on atmospheric precipitation and seasonality. However, soil moisture is subject to evaporation, especially in late autumn and summer.

The more precipitation in the autumn-winter, early spring period, the more moisture reserves accumulate in the soil and ensure high yields, regardless of future weather. Conversely, if the autumn is late and the winter is dry, the fate of the crop depends on the rainfall in late spring, and its amount is sufficient every year. In winter wheat sown areas, moisture retention is clearly observed in the $0-20 \mathrm{~cm}$ (upper) and 20-60 cm (lower) layers of the soil from the germination phase of the plant.

In dry gray soils of typical arable lands, when the soil moisture is not less than $11-12 \%$, the soil moisture is limited to $65-70 \%$ of the field moisture capacity and meets the minimum water requirements of the plant. In winter wheat sown in the furrows, soil moisture at a thickness of $0-60 \mathrm{~cm}$ is very low, with a moisture content of not less than $60-70 \%$ of the limited field moisture capacity of the soil. In dryland, in the second half of the winter wheat growth period, the water source for the plant will be the deep layers of soil (100-120 $\mathrm{cm})$. Water consumption of winter wheat is influenced by the vigorous development of plant growth organs, planting times, norms, irrigation and other technical factors. Sowing times have a significant impact on the vigorous development of the plant on irrigated lands.

Thus, a huge state program to improve the reclamation of irrigated lands and rational use of water resources in the period 2018-2020 is being implemented in the region, the gradual continuation of which will improve agricultural performance. The regional scientific-practical council established at Urgench State University within the framework of this program is strengthening this work with scientific-practical instructions.

\section{References}

1. Abdullaev S. A., Boirov A. J., Sattorov J. S. Soils of Khorezm region. Tashkent: Fan, 2002. - 190 p.

2. Ageeva E. V., Likhenko I. E., Soviets V. V., Piskarev V. V. Ecological plasticity of wheat in the forest-steppe of Western Siberia / // Bulletin of the Novosibirsk State Agrarian University. 2015. No. 1 (34). - 22-28 p.

3. Grabovets A. I., Fomenko M. A. Winter 
wheat (monograph). - Rostov-on-Don: South, 2007.-- 560 p.

4. Zhuchenko, A. A. Adaptive potential of cultivated plants (ecological and genetic basis). Chisinau: Shtiintsa, 1988.-- 767 p.

5. Zhuchenko, A. A. Strategy for adaptive intensification of agriculture (concept). Pushchino, 1994.-- 275 p.

6. Suvanov B. U. Irrigation of cotton and grain by subirrigation. A collection of articles based on the reports of the scientific-practical

conference dedicated to the 80th anniversary of UzPITI. Tashkent, 2009. 184-189 p.

7. Tadzhiev M., Tadzhiev O. The influence of winter wheat and re-crops on the agrochemical properties of soil in the southern desert zone of Uzbekistan. A collection of articles based on the reports of the scientific-practical conference dedicated to the 80th anniversary of UzPITI. Tashkent, 2009. 179-181 p.

\section{How to cite this article:}

Masharipov, A. A. and Mambetullaeva, S. M. 2021. Ecological Features of Winter Wheat Agrocenoses in the Conditions of the Khorezm Oasis in Uzbekistan. Int.J.Curr.Microbiol.App.Sci. 10(12): 183-189. doi: https://doi.org/10.20546/ijcmas.2021.1012.021 